\title{
Information-seeking Behaviour and Issues of Agriculture Undergraduates of University of Peradeniya
}

Wijetunge, P. $^{1}$

\begin{abstract}
This paper discusses the information seeking behaviour of the agriculture undergraduates in a Sri Lankan university. It established that the undergraduates often use the search engines, Wikipedia, and their own classmates than the other information resources; they use more self-taught methods than standard methods to evaluate the resources and seek help from the classmates in using the information resources. Findings further proved that their uses of various productivity tools are very low and the information-related research tasks are difficult for the majority. The paper concludes that these are the effects of inadequate information literacy (IL) training they receive and the study strongly recommends offering appropriate, context specific IL programmes, to enhance their information resource usage and research skills.
\end{abstract}

Keywords: Information-Seeking Behaviour, Agriculture Undergraduates, Information Resources, Evaluation, Productivity Tools, Research Process.

\section{Introduction}

Globally, there is a rapid growth of research literature in agriculture which makes it imperative for the students to develop their information seeking and using behavior. However, searching, accessing and using information is a complex issue for them without any support or guidance from the library and teaching staff. Understanding the trends, strengths and weaknesses of the information seeking behaviour of the agriculture students is vital for the library staff in order to provide them with a quality and relevant service.

This paper emanates from a comprehensive research on "Information seeking and research strategies of undergraduates in the digital age" carried out at University of Peradeniya during December 2012 to December 2013. The objectives of the study were to 1) to study the information seeking practices of undergraduates in the digital age, 2) to study the

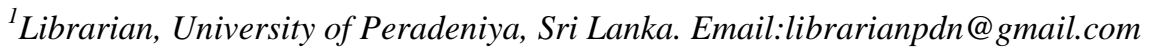


research strategies of undergraduates in the digital age and 3) to make recommendations for the future developments of the information seeking and research practices of the undergraduates.

\section{Survey of Literature}

There is little evidence of research carried out on the Sri Lankan agriculture undergraduates. Therefore, the survey of literature was extended to international studies carried out since 2000. Cheunwattana at.al. (2012) surveyed 2,435 respondents in six public universities in Thailand selected using stratified random sample with the objective studying the information literacy practices of college students in course-related and everyday-life research. The study established that the students heavily rely on search engines while their abilities in evaluating information resources were only moderate. The majority of students did not give enough importance to evaluation. Defining a topic for the assignment, narrowing down the topic, getting started on the assignment and evaluating the sources were recorded as the most difficult research-related tasks. Rhoades...et.al. (2008), surveyed 255 second and third year students enrolled in the College of Agricultural and Life Sciences of University of Florida, and established that search engines and WebCT were utilized by most. The Internet was seen to be moderately good, easy to understand, important, easy to find, beneficial, believable and credible. Hadimani and Rajgoli (2010) carried out a survey in a College of Agriculture in Rainchur, India using a questionnaire distributed to 90 randomly selected undergraduates. The study established that $94.44 \%$ know when they are in need of information, $100 \%$ know where to find information, $66.66 \%$ search Internet for information and $100 \%$ search in the college library. Of the respondents, 95.55\% are able to search exact information, $94.44 \%$ contact library staff to access information, $91.11 \%$ has the ability to evaluate information in terms of currency, authority and appropriateness. The authors have concluded that the college should have separate funding and other support for an information literacy agenda, technological infrastructure needs to be improved and that the librarians and faculty should collaborate to develop discipline-specific research skills. These conclusions imply that many development initiatives are required to increase the information skills of the undergraduates although 
their attitudes toward their information skills are highly positive according to the responses. Adio and Arinola (2012) studying 180 senior students in the Faculty of Agricultural Sciences in $\mathrm{LAUTECH}^{1}$, established that Internet was used by $74 \%$ followed by textbooks (66\%), theses and dissertations (63\%), and CD/ROM databases (39\%), and that most students lack basic knowledge and skills in using available resources and services in the library. Lack of facilities and inadequacy of computers in the library were identified as barriers. Aggressive information awareness for all students, an orientation in information searching tools and improving computer and Internet facilities are recommended.

In the Sri Lankan context, two studies on undergraduates are reported. Ileperuma and Mudannayake (2008), studied the agriculture and science undergraduates and postgrdautes and the findings established that, books are the most important information source followed by lecture notes and handouts. Electronic material had a low priority but an increasing trend to use Internet as an infromation source was perceived. Nevertheless, the paper present only the cumulative findings, therefore the specific characteristics of agriculture undergraduates cannot be known. The second study by Dilrukshi (2014) examined the usage of online journals by the fourth year undergraduates (number not specified), and established that $52 \%$ prefer online journals and $48 \%$ prefer printed journals. The study further established the barriers to the use of online journals as; the absence of proper training on using online resources, limited time available for students to search online journals, poor knowledge of online jorunals, and lack of computer facilities in the faculty. Sound awareness programmes, allocation of time in the timetables to use the library, frequent training programmes and increased computer facilities in the faculty have been recommended.

\section{Methodology}

An online questionnaire used by Head and Eisenberg (2009) was adapted to suit the Sri Lankan context and to be administered as a printed questionnaire. This instrument was

\footnotetext{
${ }^{1}$ Latoke Akintola University of Technology, Ogbomoso, Nigeria
} 
particularly considered because; access to it is open, its content and construct validity has already been established by the researchers (Head and Eisenberg 2009, 2010), and a pilot survey conducted in 2010 by the researcher proved its usability in the Sri Lankan context. Moreover, the original instrument has been used with some customizations in several other Asian countries in 2012 (i.e.Cheunwattana.et.al, 2012) therefore the findings would be comparable in the future. However, only the academic research component was used in this survey as the aim of the information seeking behavior in the academic research.

Several changes were made to make the instrument suitable for the Sri Lankan context. Instead of listing university names in Question 1 of the original instrument, a space was provided for respondents to write their university. The American terms used in Question 2 to denote the year of study were replaced with the terminology used in Sri Lanka (second, third and fourth year of study). Question 3 on disciplines, was divided in to three parts to obtain the a) faculty, b) department of study, and c) Grade Point Average of the previous year. Two new questions (Question 4 and 5) were added to obtain the age and gender of the respondents. Six new questions on the access to computers by the undergraduates and the training they have received in using the library and Internet were also added to the instrument, as comprehensive data on these were not available in the university. The final survey instrument contained 20 questions, but this paper is based on the data gathered on, types of assignments the students have to answer, types of information resources used often, methods used to evaluate them, and difficulty of research related information tasks as encountered by the undergraduates.

Since access to e-mail by the students is limited, a printed version of the questionnaire was administered through the faculty library in early 2013 and the data collection was completed within two months. Faculty web sites and annual reports as well as some faculty members and the Senior Assistant Librarian of the faculty were used to triangulate the findings. To provide the theoretical foundations for the study and the findings, international and Sri Lankan research literature related to information seeking behaviour of agriculturalists was used. Of 688 students in their second, third and fourth years, $10 \%$ were 
selected using Stratified Random Sample method. The questionnaire was administered through the faculty library and the departments and the response rates were $92 \%, 100 \%$ and $100 \%$ respectively, while the overall response rate was $97 \%$. First year students were disregarded as their use of information was not expected to be advanced enough to respond to the questionnaire effectively. This paper discusses the findings of all students surveyed instead of making a year-wise analysis.

Students were given seven choices ${ }^{1}$, as in the original survey to express their responses on frequency of using information resources and methods of evaluating them. In presenting data, the response categories "Almost Always" and "Often" were conflated in to a new category of "Often Used". For difficulties of course-related research also, seven choices ${ }^{2}$ were given and Strongly Agree and Somewhat Agree were conflated into "Agree". These two new categories were used to present the findings throughout this paper. The rest of the categories (Sometimes - No Experience ${ }^{3}$ and Neither Agree Nor Disagree - No Experience with this Situation ${ }^{4}$ ) were not considered for the analysis as the number of responses for these categories were extremely few and would not have made any significant change in the findings. MS. Excel was used to quantitatively analyze and present findings graphically.

As the responses are personal judgments of the respondents, of their information seeking strategies, and the findings of the survey are mostly based on their responses, the reliability of the findings largely depends on the accuracy of their revelations. Nevertheless, the findings can be generalized to the total student body of the faculty as the sample is representative and the student cohorts are principally homogenous.

\footnotetext{
${ }^{1}$ Almost Always, Often, Sometimes, Rarely, Never, Do Not Know and No Experience

${ }^{2}$ Strongly Agree, Somewhat Agree, Neither Agree Nor Disagree, Somewhat Disagree, Strongly Disagree, Don't know, No Experience with this Situation.
} 


\section{Findings}

The following sections discuss the findings under several themes; age, gender and GPA of the respondents, types of assignments received, resources consulted, evalution criteria, people asked for assistantce with evaluation of material, and difficulty of tasks related to course-related research.

\section{Age, Gender and GPA of the Respondents}

Of the total respondents, the majority (66\%) were in the age group of $24-26$ years, $51 \%$ were females and, 55\% had received a Grade Point Average (GPA) of 3.0-3.5 Table 1 presents the details.

Table 1: Age, Gender and GPA of the Respondents

\begin{tabular}{|c|c|c|}
\hline Aspect & Frq. & $\%$ \\
\hline \multicolumn{3}{|l|}{ Age } \\
\hline $18-20$ & 0 & 0 \\
\hline $21-23$ & 3 & 4 \\
\hline $24-26$ & 44 & 66 \\
\hline over 26 & 20 & 30 \\
\hline \multicolumn{3}{|l|}{ Gender } \\
\hline Male & 33 & 49 \\
\hline Female & 34 & 51 \\
\hline \multicolumn{3}{|l|}{ GPA } \\
\hline $2.0-2.5$ & 0 & 0 \\
\hline $2.6-2.9$ & 7 & 10 \\
\hline $3.0-3.5$ & 37 & 55 \\
\hline 3.6- above & 23 & 34 \\
\hline Not given & 0 & 0 \\
\hline
\end{tabular}




\section{Types of Assignments Received}

Table 2 depicts the types of assignments they receive during their study period. Sixty one percent $(61 \%)$ stated that they receive "Oral presentations" and 52\% commented that they receive "Papers that present a case study analysis" while $49 \%$ confirmed that they receive "Multimedia product preparation that requires research". These findings denote that they have been provided with many opportunities to use a wide variety of information resources for their course-related research.

Table 2: Types of Assignments Received

\begin{tabular}{|l|c|c|}
\hline \multicolumn{1}{|c|}{ Types of Assignments } & Frq. & $\%$ \\
\hline 1.Papers that present an argument about an issue (s) & 41 & 59 \\
\hline 2.Papers that present a historical analysis of an event (s) & 35 & 51 \\
\hline $\begin{array}{l}\text { 3.Papers that present a "close reading" or interpretation of a } \\
\text { text }\end{array}$ & 33 & 48 \\
\hline 4.Papers that present a case study analysis & 36 & 52 \\
\hline 5.Papers that present a literature review & 46 & 67 \\
\hline 6.Papers that present a proposed study & 53 & 77 \\
\hline 7.Oral presentation & 42 & 61 \\
\hline 8.Oral presentation and accompanying paper & 47 & 68 \\
\hline 9.Multimedia product that requires research & 43 & 62 \\
\hline
\end{tabular}

\section{Resources Consulted}

Three types of resources they used were surveyed; digital, human and printed (Table 3). Of the digital resources the most often used were the search engines (96\%) and Wikipedia (73\%), but only $18 \%$ often used full text databases. Of the human resources, classmates $(66 \%)$, lecturers (64\%), and friends and family (37\%) were the most often used. Of the 
Journal of the University Librarians Association of Sri Lanka, Vol.18, Issue 2, June 2014

printed resources, recommended readings (58\%), and the library collections (45\%) were the most often used while $40 \%$ used their personal collections.

Table 3: Resources Consulted

\begin{tabular}{|l|c|c|c|c|c|c|c|c|}
\hline \multicolumn{1}{|l|}{ Resources Consulted } & $\mathbf{O}$ & $\mathbf{\%}$ & $\mathbf{S}$ & $\mathbf{\%}$ & $\mathbf{N}$ & $\mathbf{\%}$ & $\mathbf{D} / \mathbf{N}$ & $\mathbf{\%}$ \\
\hline 1. Recommended readings & 39 & 58 & 28 & 42 & 1 & 1 & 1 & 1 \\
\hline 2. Search Engines & 64 & 96 & 5 & 7 & 0 & 0 & 0 & 0 \\
\hline 3. Wikipedia & 49 & 73 & 17 & 25 & 1 & 1 & 1 & 1 \\
\hline $\begin{array}{l}\text { 4. Government Web Sites } \\
\text { 5. E-resources through the } \\
\text { library }\end{array}$ & 12 & 18 & 32 & 48 & 13 & 19 & 10 & 15 \\
\hline 6. Librarians & 14 & 21 & 38 & 57 & 7 & 10 & 5 & 7 \\
\hline 7. Library Collection & 30 & 45 & 27 & 40 & 5 & 7 & 2 & 3 \\
\hline 8. Lecturers & 43 & 64 & 19 & 28 & 3 & 4 & 1 & 1 \\
\hline 9. Classmates & 44 & 66 & 23 & 34 & 0 & 0 & 0 & 0 \\
\hline 10. Friends/family & 25 & 37 & 28 & 42 & 9 & 13 & 2 & 3 \\
\hline 11. Personal Collection & 27 & 40 & 27 & 40 & 6 & 9 & 6 & 9 \\
\hline
\end{tabular}

$\mathrm{O}-$ Often $\mathrm{S}-$ Sometimes $\mathrm{N}-$ Never $\mathrm{D} / \mathrm{N}-$ Don't Know/No Experience 


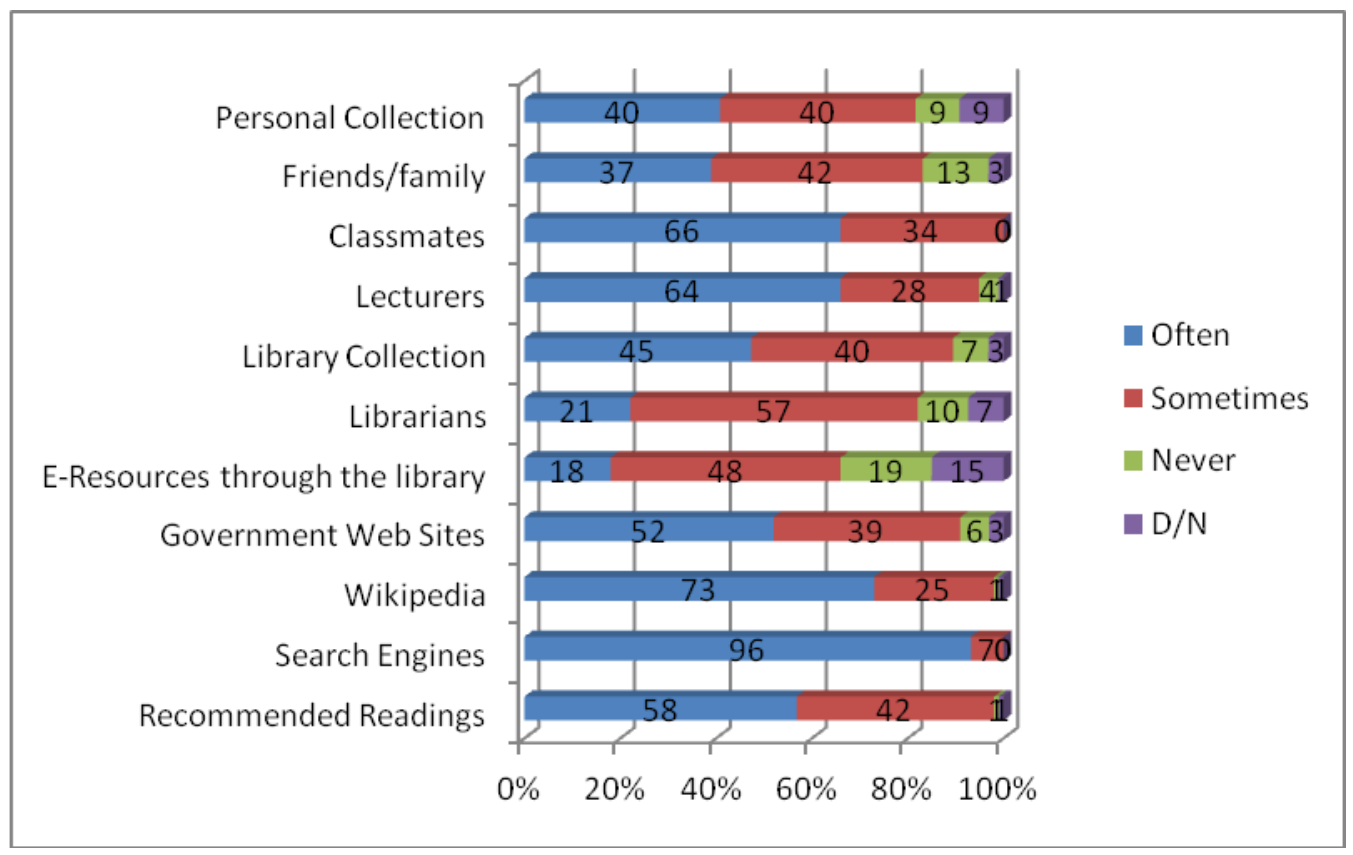

Figure 1: Resources Consulted

\section{Evaluation Criteria}

This section surveyed two aspects; criteria used to evaluate library material and criteria used to evaluate web-based material. Respondents were offered ten criteria (Table 4 and Figure 2) to select according the frequency they used each criteria to evaluate library material. In evaluating library material, $61 \%$ each considered the currency of the book, and, whether the charts of the item contain vital information. Whether they have used the item before, is considered by $46 \%$. The reputation of the publisher and whether the respondents have heard about the item before, is considered each by $39 \%$. Authors' credentials are used by $25 \%$ while librarians' recommendation is considered by $16 \%$. 
Journal of the University Librarians Association of Sri Lanka, Vol.18, Issue 2, June 2014

Table 4: Criteria used to evaluate library resources

\begin{tabular}{|l|l|l|l|l|l|l|l|l|}
\hline \multicolumn{1}{|c|}{ Criteria } & $\mathbf{O}$ & $\mathbf{\%}$ & $\mathbf{S}$ & $\mathbf{\%}$ & $\mathbf{N}$ & $\mathbf{\%}$ & $\mathbf{D} / \mathbf{N}$ & $\mathbf{\%}$ \\
\hline 1.Currency of book / article & 41 & 61 & 26 & 39 & 0 & 0 & 2 & 3 \\
\hline 2. Author's credentials & 17 & 25 & 39 & 58 & 10 & 15 & 3 & 4 \\
\hline 3. Availability of Acknowledgements & 22 & 33 & 39 & 58 & 4 & 6 & 4 & 6 \\
\hline 4. Author gives credit & 14 & 21 & 42 & 63 & 7 & 10 & 6 & 9 \\
\hline 5. Book / article has a bibliography & 11 & 16 & 36 & 54 & 6 & 9 & 11 & 16 \\
\hline 6. Whether charts have vital information & 41 & 61 & 19 & 28 & 3 & 4 & 4 & 6 \\
\hline 7.Publisher of the book / journal & 26 & 39 & 27 & 40 & 11 & 16 & 3 & 4 \\
\hline 8. Librarian recommended the book / article & 11 & 16 & 41 & 61 & 10 & 15 & 6 & 9 \\
\hline 9. Have heard of the book / article before & 26 & 39 & 36 & 54 & 6 & 9 & 0 & 0 \\
\hline \begin{tabular}{l} 
10.Have used the book / article before \\
\hline
\end{tabular} & 31 & 46 & 30 & 45 & 7 & 10 & 0 & 0 \\
\hline
\end{tabular}

$\mathrm{O}-$ Often $\mathrm{S}-$ Sometimes $\mathrm{N}-$ Never $\mathrm{D} / \mathrm{N}-$ Don't Know/No Experience 


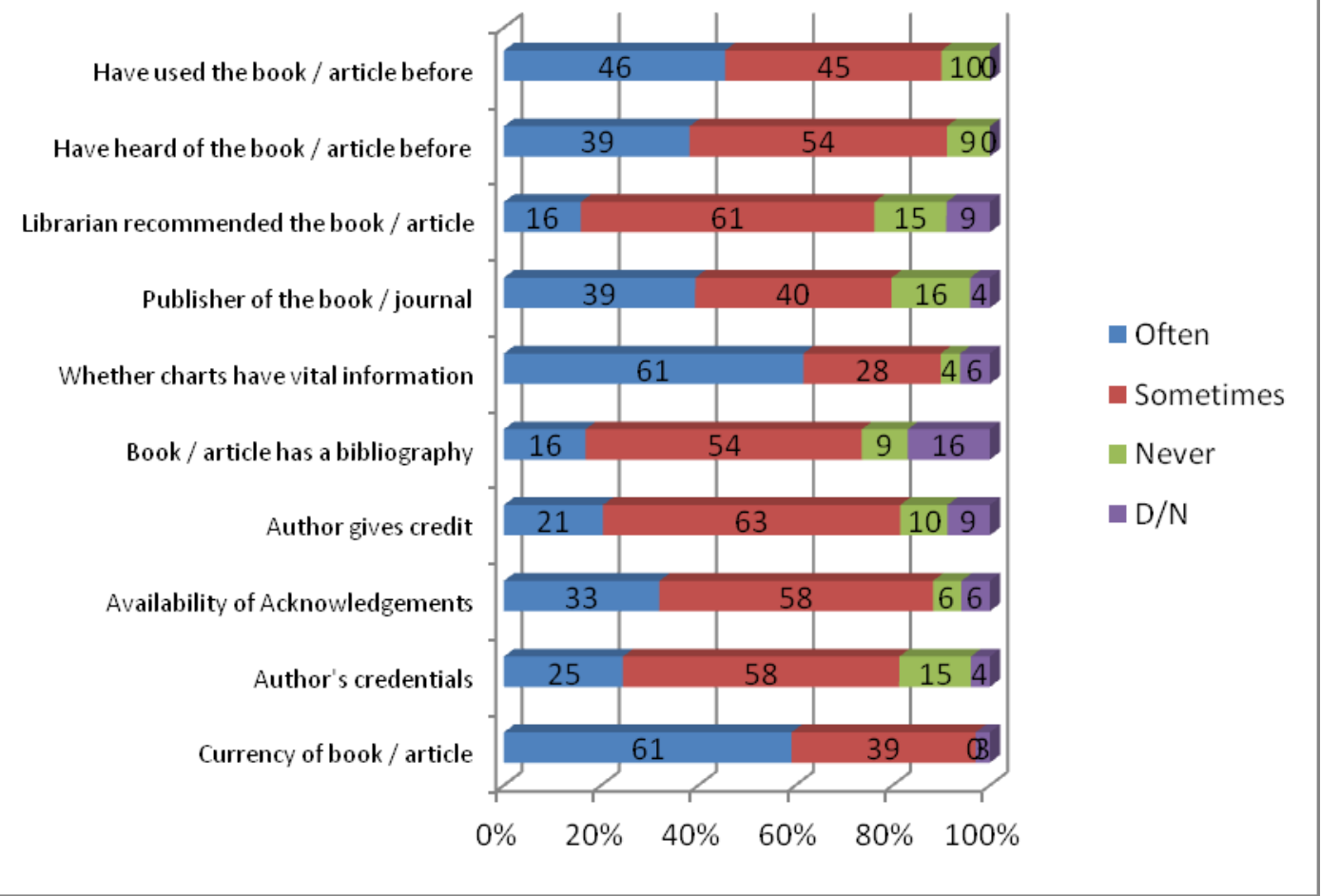

Figure 2 : Criteria used to evaluate library resources

Respondents were offered twelve criteria (Table 5 and Figure 3) to select according to the frequency they used each to evaluate web-based resources. Currency of the website (63\%), availability of vital information in the charts of the item (60\%), while, $48 \%$ each considered whether they have heard of the website before $(48 \%)$ or used the website before $(48 \%)$ and whether the website has links to the other resources (43\%). URL (34\%), design of the website $(30 \%)$ and librarians recommendations (13\%) are not used by many. 
Table 5: Criteria used to evaluate web-based resources

\begin{tabular}{|c|c|c|c|c|c|c|c|c|}
\hline Criteria & $\mathbf{O}$ & $\%$ & $\mathbf{S}$ & $\%$ & $\mathbf{N}$ & $\%$ & $\mathrm{D} / \mathrm{N}$ & $\%$ \\
\hline 1. How current the Web Site is. & 42 & 63 & 24 & 36 & 2 & 3 & 1 & 1 \\
\hline 2. Web site author's credentials & 19 & 28 & 35 & 52 & 12 & 18 & 3 & 4 \\
\hline $\begin{array}{l}\text { 3. content acknowledges different } \\
\text { viewpoints }\end{array}$ & 24 & 36 & 36 & 54 & 7 & 10 & 2 & 3 \\
\hline $\begin{array}{l}\text { 4. Web site gives credit for using someone } \\
\text { else's ideas. }\end{array}$ & 18 & 27 & 39 & 58 & 6 & 9 & 6 & 9 \\
\hline 5. Consider what the URL mean & 23 & 34 & 33 & 49 & 10 & 15 & 3 & 4 \\
\hline $\begin{array}{l}\text { 6. Web site has links to other resources on } \\
\text { the Web. }\end{array}$ & 29 & 43 & 34 & 51 & 3 & 4 & 1 & 1 \\
\hline 7. Web site has bibliography. & 14 & 21 & 30 & 45 & 4 & 6 & 19 & 28 \\
\hline 8. vital information of charts & 40 & 60 & 24 & 36 & 3 & 4 & 2 & 3 \\
\hline $\begin{array}{l}\text { 9. A librarian recommended using the } \\
\text { Web site. }\end{array}$ & 9 & 13 & 43 & 64 & 9 & 13 & 7 & 10 \\
\hline $\begin{array}{l}\text { 10. Consider whether I have ever } \\
\text { heard of the Web site before. }\end{array}$ & 32 & 48 & 26 & 39 & 7 & 10 & 1 & 1 \\
\hline 11. I have used the Web site before. & 32 & 48 & 31 & 46 & 4 & 6 & 1 & 1 \\
\hline $\begin{array}{l}\text { 12. Web site's design tells me it's a } \\
\text { legitimate site. }\end{array}$ & 20 & 30 & 33 & 49 & 5 & 7 & 10 & 15 \\
\hline
\end{tabular}

$\mathrm{O}-$ Often $\mathrm{S}-$ Sometimes $\mathrm{N}-$ Never $\mathrm{D} / \mathrm{N}-$ Don't Know/No Experience 


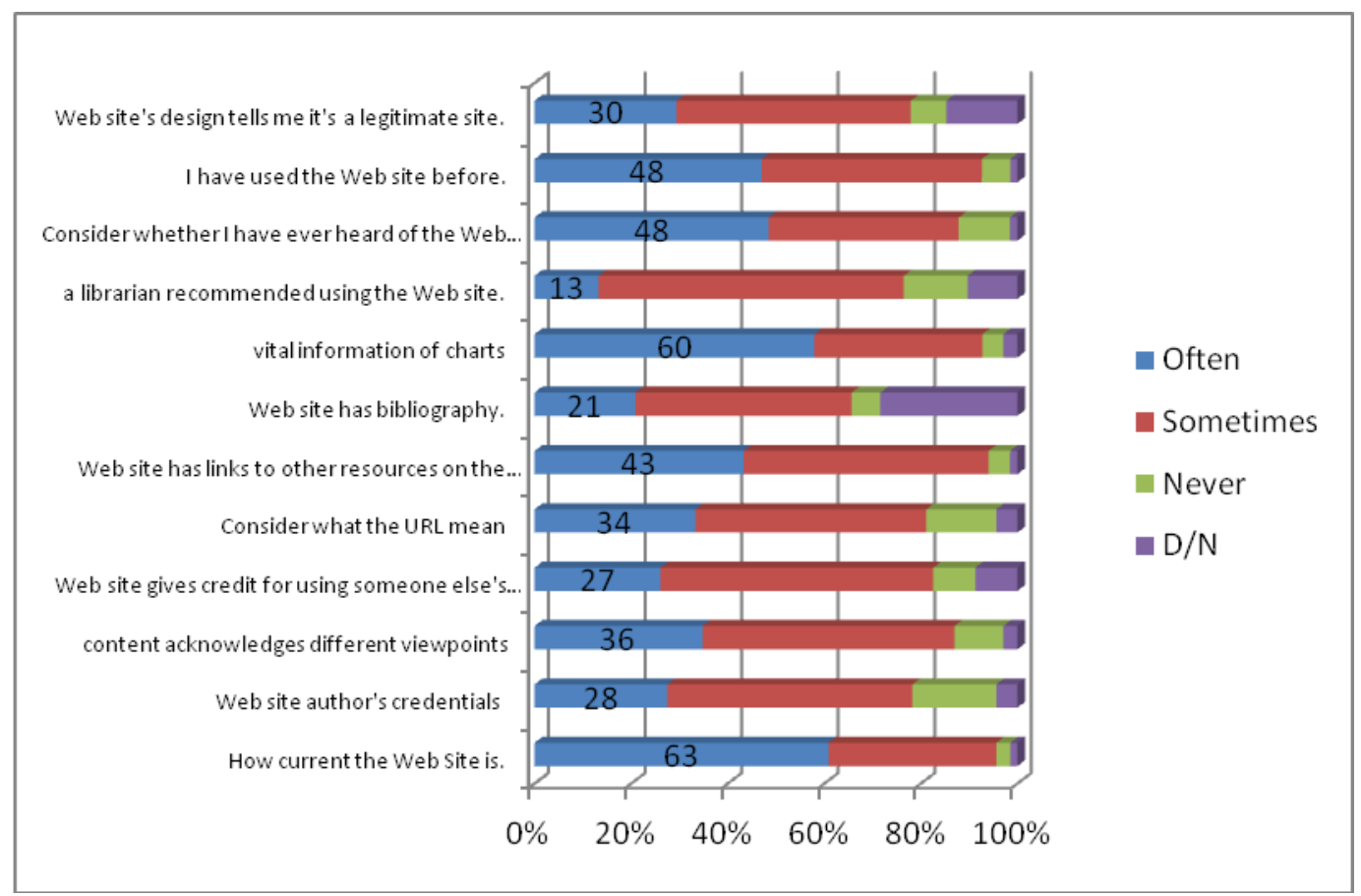

Figure 3 : Criteria used to evaluate web-based resources

\section{People Asked for Assistance}

The respondents were asked about the people they consult when they need assistance in selecting the most relevant information resources from the plethora (Table 6 and Figure 4). Classmates are the most consulted group (by 61\%) followed by lecturers (52\%), and friends and family (by 40\%) and licensed professionals (18\%). Only $10 \%$ claimed that they consult librarians. 
Table 6 - People Asked for Assistance

\begin{tabular}{|l|c|c|c|c|c|c|c|c|}
\hline People Asked for Assistance & $\mathbf{O}$ & $\mathbf{\%}$ & $\mathbf{S}$ & $\mathbf{\%}$ & $\mathbf{N}$ & $\mathbf{\%}$ & $\mathbf{D} / \mathbf{N}$ & $\mathbf{D} / \mathbf{N}$ \\
\hline 1.Lecturers & 35 & 52 & 29 & 43 & 5 & 7 & 0 & 0 \\
\hline 2.Librarians & 7 & 10 & 46 & 69 & 14 & 21 & 2 & 3 \\
\hline 3.Classmates & 41 & 61 & 26 & 39 & 1 & 1 & 1 & 1 \\
\hline 4.Friends and family & 27 & 40 & 31 & 46 & 9 & 13 & 1 & 1 \\
\hline 5.Licensed professionals & 12 & 18 & 29 & 43 & 17 & 25 & 10 & 15 \\
\hline
\end{tabular}

$\mathrm{O}-$ Often $\quad \mathrm{S}-$ Sometimes $\mathrm{N}-\mathrm{Never} \mathrm{D} / \mathrm{N}-$ Don't Know/No Experience

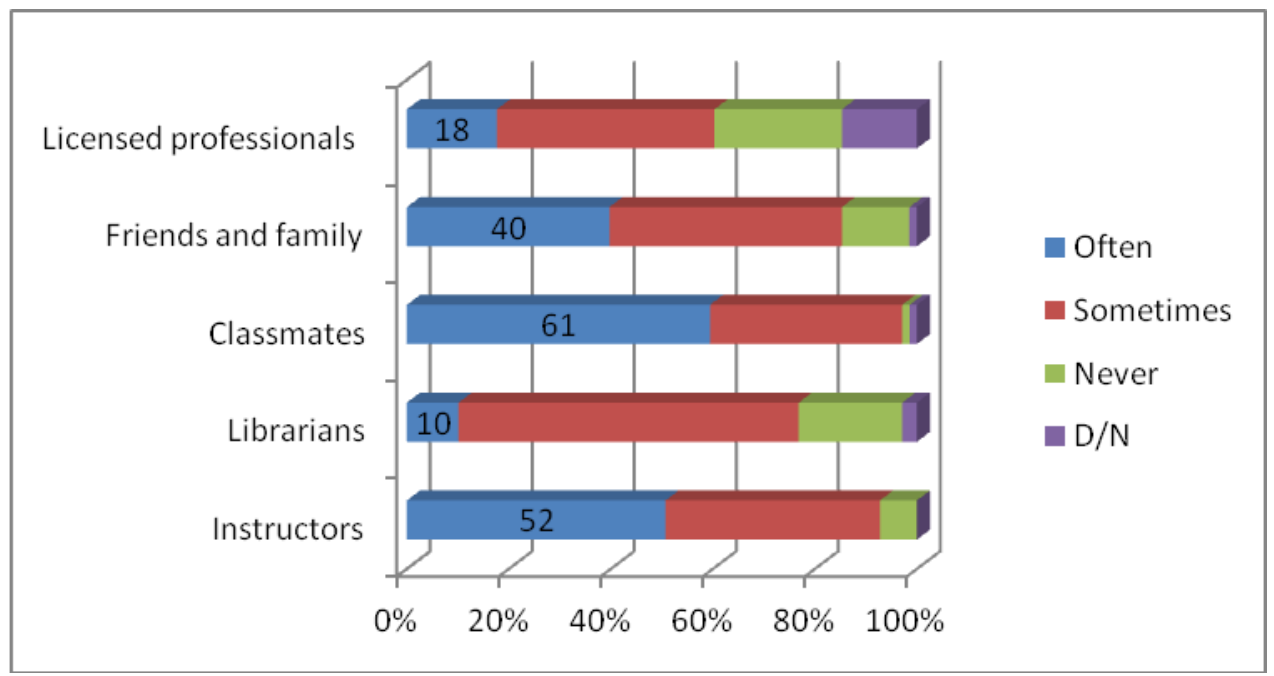

Figure 4 : People asked for assistance

\section{Use of Productivity Tools}

Use of Productivity Tools were anaylsed under three headings; software solutions, Web 2.0, and Virtual Research Environment (Table 7 and Figure 5). Of the Software solutions, $60 \%$ use highlighting features, $21 \%$ use digital sticky notes but only $12 \%$ use citationmaking programs like End Note. Of the Web 2.0 elements, a higher percentage (69\%) uses only the document sharing but others (social bookmarking, microblogs and blogging, 
Journal of the University Librarians Association of Sri Lanka, Vol.18, Issue 2, June 2014

online time management programs, wikis, photo-sharing sites, voice over Internet (Skype) as well virtual research environments are used by, less than $50 \%$ of the students.

Table 7: Use of Productivity tools

\begin{tabular}{|c|c|c|c|c|c|c|c|c|}
\hline Productivity Tools & $\mathbf{U}$ & $\%$ & $\mathbf{N U}$ & $\%$ & $\overline{D R}$ & $\%$ & $\mathrm{D} / \mathrm{N}$ & $\%$ \\
\hline \multicolumn{9}{|l|}{ Software Solutions } \\
\hline $\begin{array}{l}\text { 1. Highlighting feature on a computer } \\
\text { screen }\end{array}$ & 40 & 60 & 9 & 13 & 7 & 10 & 1 & 1 \\
\hline 2. Digital "sticky notes" & 14 & 21 & 23 & 34 & 12 & 18 & 8 & 12 \\
\hline 3. Citation-making programs & 8 & 12 & 24 & 36 & 13 & 19 & 12 & 18 \\
\hline \multicolumn{9}{|l|}{ Web 2.0} \\
\hline $\begin{array}{l}\text { 4. Social bookmarking (e.g., digg, } \\
\text { delicious) }\end{array}$ & 11 & 16 & 25 & 37 & 11 & 16 & 10 & 15 \\
\hline 5. Microblogs (i.e., Twitter) & 15 & 22 & 27 & 40 & 8 & 12 & 7 & 10 \\
\hline 6. Document sharing programs & 46 & 69 & 9 & 13 & 1 & 1 & 1 & 1 \\
\hline $\begin{array}{l}\text { 7. Online time mgt. programs with } \\
\text { sharing }\end{array}$ & 17 & 25 & 28 & 42 & 9 & 13 & 2 & 3 \\
\hline 8. Wikis & 22 & 33 & 22 & 33 & 7 & 10 & 3 & 4 \\
\hline 9. Photo-sharing sites & 15 & 22 & 29 & 43 & 8 & 12 & 5 & 7 \\
\hline 10. Blogging & 20 & 30 & 27 & 40 & 9 & 13 & 1 & 1 \\
\hline 11. Voice over Internet Protocol & 19 & 28 & 28 & 42 & 9 & 13 & 1 & 1 \\
\hline $\begin{array}{l}\text { 12. An online forum where I can post a } \\
\text { question and get an answer from } \\
\text { someone }\end{array}$ & 19 & 28 & 28 & 42 & 9 & 13 & 0 & 0 \\
\hline \multicolumn{9}{|l|}{ Virtual Research Environments } \\
\hline 13. Alerting services & 15 & 22 & 22 & 33 & 11 & 16 & 8 & 12 \\
\hline 14. Virtual research environments & 12 & 18 & 26 & 39 & 9 & 13 & 8 & 12 \\
\hline
\end{tabular}

U- Used NU - Not Used DR - Don’t Remember D/N - Do not Know / No Experience 


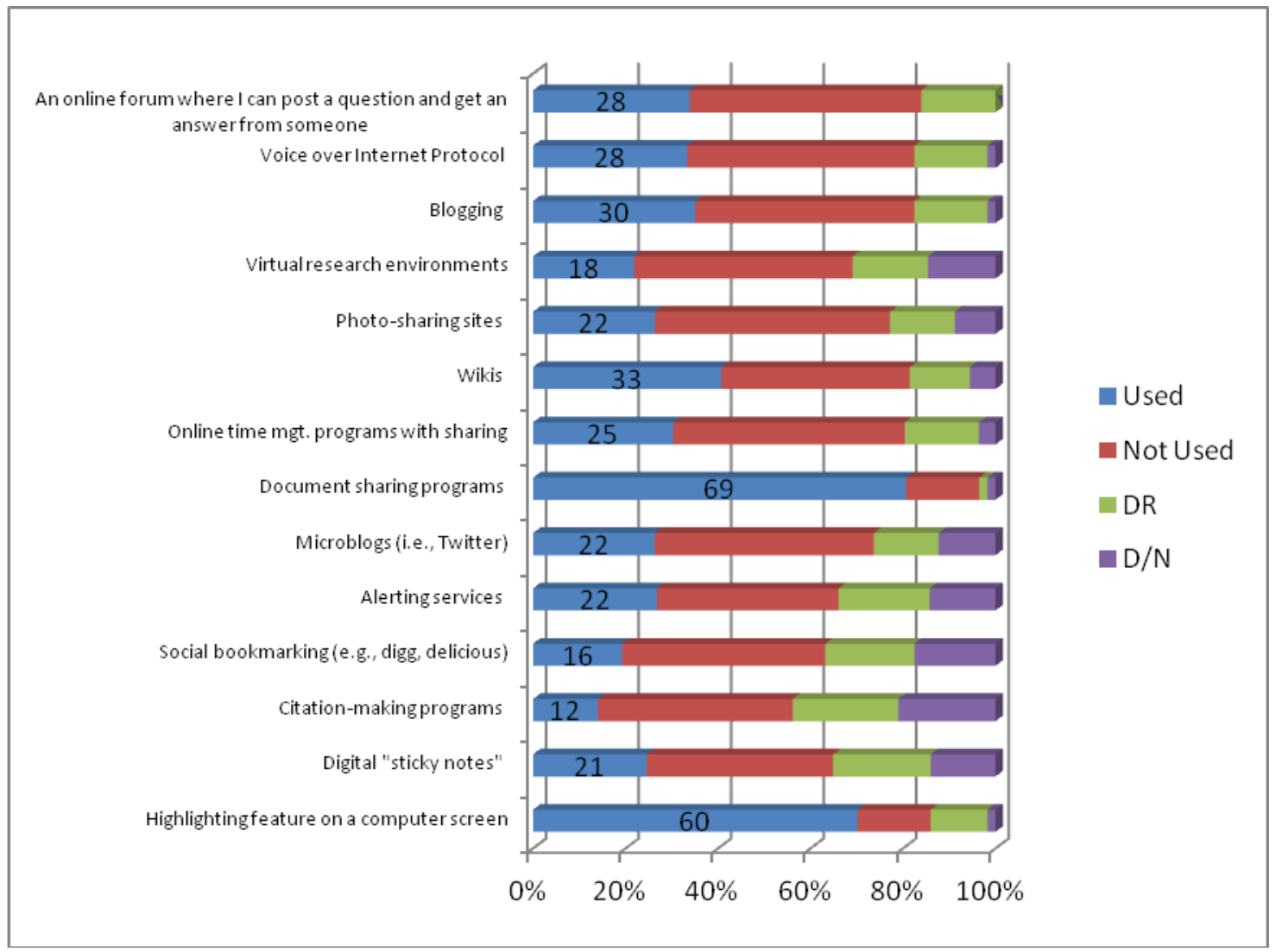

Figure 5 : Use of Productivity Tools

\section{Difficulty of Tasks}

Respondents were presented with twenty different tasks related to getting started, searching, evaluating, using, citing information, and completing the assignment writing process and were asked to state their opinion on the difficulty of these tasks (Table 8 and Figure 6) .Of the starting process, $76 \%$ confirmed that starting is difficult while $72 \%$ found narrowing down the topic is difficult and defining the topic of the assignment was difficult for $67 \%$. With regard to searching for information, $58 \%$ claimed that finding up-to-date material is difficult and 55\% expressed that sorting through irrelevant results to find what is relevant is difficult, while $52 \%$ confirmed that it is difficult to find the information within the different parts of the university. For $42 \%$, identifying the keywords to be used was difficult while for 
$37 \%$, finding articles from the library databases were difficult. Finding information from Internet was difficult for $33 \%$. As far as evaluating of sources is concerned, $49 \%$ agreed that determining the credibility of a web site is difficult while $48 \%$ agreed that evaluating the sources is difficult.

As far as using the information is concerned, $48 \%$ agreed reading through the material is often difficult and for $36 \%$ writing is often difficult. As far as the citing is concerned, $37 \%$ agreed that they often have a difficulty in knowing when to cite and for $33 \%$ it is often difficult to know how to cite a source and 31\% 38\% agreed that knowing whether the use of a source in certain circumstances constitutes plagiarism or not is often difficult. With regard to completing the process, $36 \%$ claimed that it is often difficult to know whether a "good job" is done or not and $31 \%$ claimed that deciding whether the writing is finished or not is difficult.

Table 8 : Difficulty of Tasks

\begin{tabular}{|c|c|c|c|c|c|c|c|c|}
\hline Difficulty of Tasks & $\mathbf{A}$ & $\%$ & A? & $\%$ & $\mathbf{D A}$ & $\%$ & $\mathbf{D} / \mathbf{N}$ & $\%$ \\
\hline \multicolumn{9}{|l|}{ Starting process } \\
\hline 1. Getting started on the assignment is difficult. & 51 & 76 & 8 & 12 & 5 & 7 & 1 & 1 \\
\hline 2. Defining a topic for the assignment is difficult. & 45 & 67 & 10 & 15 & 9 & 13 & 1 & 1 \\
\hline 3. Narrowing down a topic is difficult. & 48 & 72 & 10 & 15 & 6 & 9 & 1 & 1 \\
\hline \multicolumn{9}{|l|}{ Searching } \\
\hline 4. Coming up with key words is difficult. & 28 & 42 & 18 & 27 & 16 & 24 & 2 & 3 \\
\hline $\begin{array}{l}\text { 5. Finding articles in the databases on the } \\
\text { library's Web site is difficult }\end{array}$ & 25 & 37 & 15 & 22 & 13 & 19 & 11 & 16 \\
\hline 6. Finding sources from Internet is difficult & 22 & 33 & 7 & 10 & 33 & 49 & 3 & 4 \\
\hline $\begin{array}{l}\text { 7. Figuring out where to find sources in different } \\
\text { parts of the university is difficult. }\end{array}$ & 35 & 52 & 16 & 24 & 7 & 10 & 6 & 9 \\
\hline
\end{tabular}


Journal of the University Librarians Association of Sri Lanka, Vol.18, Issue 2, June 2014

\begin{tabular}{|l|l|l|l|l|l|l|l|l|l|} 
8. Finding up-to-date materials is difficult. & 39 & 58 & 16 & 24 & 7 & 10 & 3 & 4 \\
\hline $\begin{array}{l}\text { Having to sort through all the irrelevant results } \\
\text { I get to find what I need is difficult. }\end{array}$ & 37 & 55 & 15 & 22 & 10 & 15 & 2 & 3 \\
\hline
\end{tabular}

\section{Evaluation}

10. Determining whether a Web Site is credible or not is difficult.

11. Evaluating the sources I've found is difficult.

\begin{tabular}{|l|l|l|l|l|l|l|l|}
\hline 33 & 49 & 13 & 19 & 14 & 21 & 4 & 6 \\
\hline 32 & 48 & 18 & 27 & 11 & 16 & 2 & 3 \\
\hline
\end{tabular}

\section{Using Information}

13. Reading through the material is difficult.

14. Taking notes is difficult.

15. Integrating different sources into my assignment is difficult.

16. Writing is difficult.

\begin{tabular}{|l|l|l|l|l|l|l|l|}
\hline 32 & 48 & 13 & 19 & 18 & 27 & 2 & 3 \\
\hline 23 & 34 & 11 & 16 & 28 & 42 & 3 & 4 \\
\hline 22 & 33 & 20 & 30 & 18 & 27 & 4 & 6 \\
\hline 24 & 36 & 11 & 16 & 25 & 37 & 3 & 4 \\
\hline
\end{tabular}

\section{Citing}

17. Knowing when I should cite a source is difficult.

18. Knowing how to cite a source in the right format is difficult.

19. Knowing whether my use of a source, in certain circumstances, constitutes plagiarism or not is difficult.

\section{Completing Process}

20. Deciding whether "I'm done" or not is difficult.

21. Knowing whether I've done a good job on the assignment or not is difficult.

A - Agree A? Neither Agree Nor Disagree $\mathrm{D}$ - Disagree $\mathrm{D} / \mathrm{N}$ - Do not Know/No

Experience 


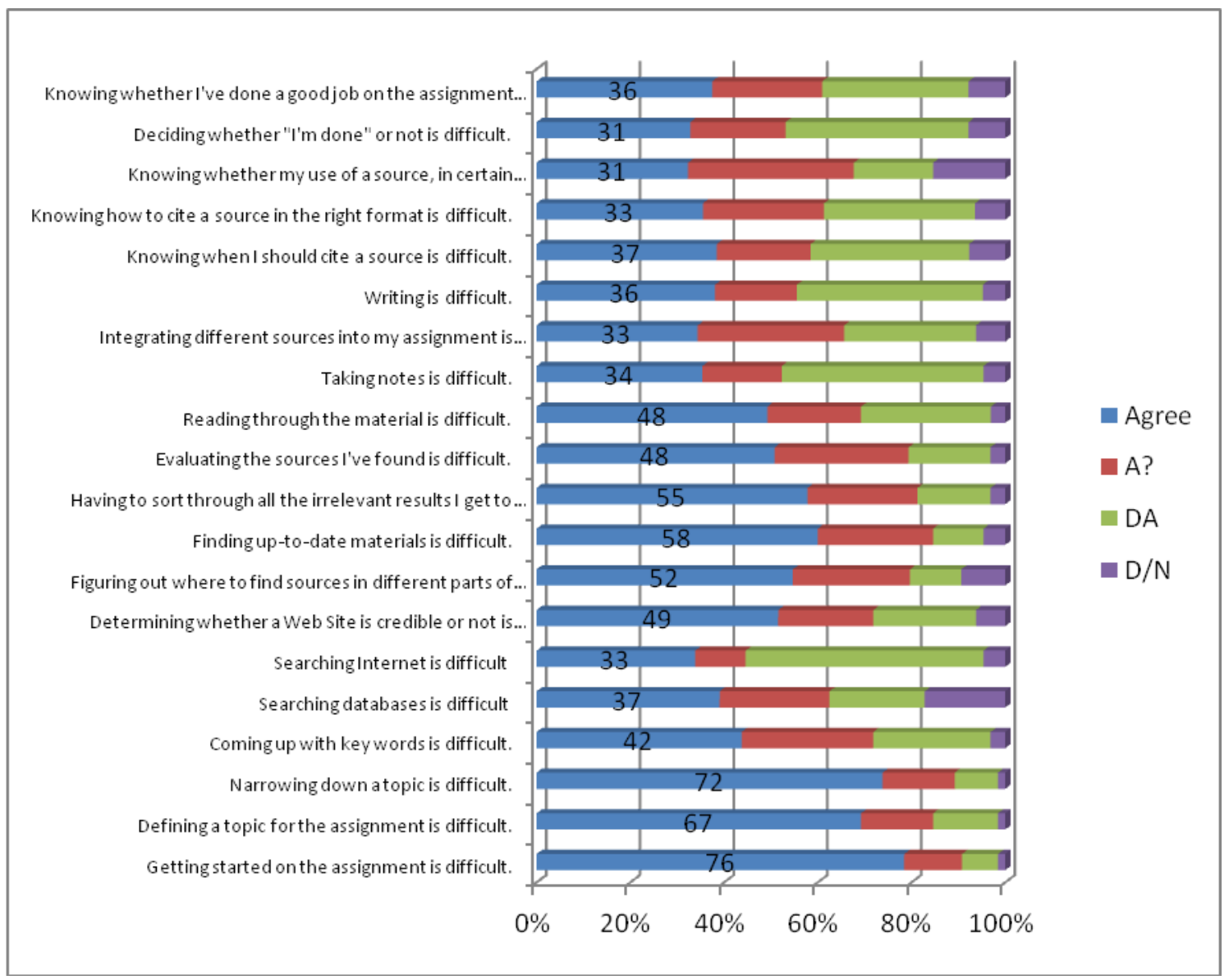

\section{A - Agree A? Neither Agree Nor Disagree $\quad$ D - Disagree $\quad$ D/N - Do not Know/No Experience}

Figure 6 : Difficulty of tasks 


\section{Discussion}

Findings indicated that the agriculture undergraduates prefer search engines (96\%) and Wikipedia (73\%), to the other types of resources. This trend is in conformity with the previous research of Adio and Arinola (2012), Cheunwattana et.al. (2012) and Rhoades...et.al. (2008). According to these surveys, students perceive Internet as the most effective method of obtaining information because it is easy to understand, important, beneficial, and accurate. Head and Eisenberg $(2009,2010)$ also established that it meets the students' requirements in terms of currency, coverage, convenience, and comprehensibility while Colon-Aguirre and Fleming-May established that, the students prefer Wikipedia because of its capacity to help them with the terms and use of language regarding certain topics, its clarity of language and inclusion of hyperlinked citations. Lim identified ability to check facts quickly and the availability of background information, as reasons for the students' preference of Wikipedia over the other information resources.

The study also established that the agriculture undergraduates' third preference is classmates $(66 \%)$, as an information resource, which is contrary to the other studies reported here. Sixty one percent (61\%) also seek assistance from their classmates in evaluating information resources. While further in-depth study is required to confirm why such a higher percentage of Sri Lankan agriculture undergraduates turn to their classmates for support with their research, findings of a previous study throw some light on this trend. Lee, Paik, and Joo (2012) ascertained that the undergraduates in their study used their friends and colleagues for comparison of findings with one's own, to obtain advice on a task and to obtain advice on search process. They further established that the colleagues and friends are used because of ease of accessibility, efficiency, and understanding.

Their fourth preference is the lecturers as an information resource (64\%) and 52\% also turn to lecturers when they need assistance. This trend has been perceived by the other studies reported here. Head and Eisenberg (2009) identified several reasons for the students turning to their lecturers for information; because they graded the assignments of the students, they 
are available through e-mail, provided guidelines, reviewed draft provided by the students, engaged in individual sessions with the students and had in-class discussions. In other words, lecturers had closer interactions with the students with regard to their course related research than the librarians did, therefore they turn towards the lecturers for information.

However, their use of library collection is low (45\%) and only $21 \%$ considered librarians as an information source while only $10 \%$ turned to librarians for assistance with using information resources. The inadequate use of library is also a trend prevailing in accordance with the global trend. Inconvenience, lack of time, confusion over how to begin the search for resources, having problems with navigating the mechanisms to locate materials, and getting intimidated by seeking assistance from the staff in addition to library anxiety are perceived as reasons for the low use of the library (Colon-Aguirre and Fleming-May 2012). Adio and Arinola (2012), established that the constraints faced by the students are; the unwillingness of the library staff to assist them, inadequacy of library opening hours, lack of relevant books, periodicals and other information resources in library. The current study did not make an in-depth analysis of usage pattern of the library by the agriculture students, but it was observed that there is a considerable distance between the lecture theatres and the library, which can make it inconvenient for the students to visit the library frequently while attending lectures. However, further research would be required to make any comments about why the usage is low.

Several studies have established why student prefer certain information resources over the others, even if the librarians and their teachers perceive that certain other resources are better in quality than what the students prefer. It indicates that the Sri Lankan respondents select their information resources based on convenience and ease of access.

Head and Eisenberg (2009) have identified three criteria (Traditional standards of timeliness and authority, Domain specific standards, and Self-taught standards) for evaluating information resources. Findings indicated that the respondents use one traditional (currency) and two self-taught methods (previously used, and availability of vital information in charts of the item) often, to evaluate the library material. They often use 
three self-taught methods (previously heard, previous use, and availability of vital information in charts) and one traditional method (currency) to evaluate Internet-based resources. Although Head and Eisenberg established that their subjects evaluate internetbased material more than the library material, this was not evident in this Sri Lankan study. The percentages of students who use evaluation methods were almost equal for both types of resources. It was observed that the use of reliable evaluation methods was not adequate. Their evaluation methods need to be improved especially as they often use search engines, Wikipedia, and classmates more than the other more reliable resources.

Very low use of productivity tools by the respondents are similar to that of Head and Eisenberg (2010). They established that, except the highlighting features (by 62\%), citation making programmes (by 55\%) and document sharing programmes (by 48\%) other tools are not adequately used for academic research. Cheunwattana et.al. (2012) also established that the respondent' use productivity tools is not significant. Head and Eisenberg (2010) opined that "even though the students may be heavy users of social networking sites such as Facebook, Web 2.0 applications for academic research have not yet found their way into students' research repertoire - yet" (Head and Eisenberg (2010, p. 23). However, a study carried out in Malaysia (Zakaria, Watson and Edwards 2010) has confirmed that the general opinion about integrating Web 2.0 tools in to learning is positive although some degree of inexperience and hesitancy was noted in particular tools. Students are passive in the context of content construction but regularly download information. Kumar (2009) presenting the findings of a study undergraduate perceptions of the usefulness of Web 2.0 comment that students' familiarity with the new technologies for other purposes, does not always translate to their use of those technologies for learning. She further comments that the students welcome the use of technologies for teaching and learning when they have had prior successful experience with them. In her study, the familiarity of the students with certain technologies like Facebook, outside education, made it possible for them to reflect on their educational value. 
Students' lack of knowledge in routine research practices was ascertained by the findings on their difficulties of research related tasks implying that their research related information skills are considerably low. Of the ten most difficult tasks for them, three are related with the starting process and the other seven are related to evaluation of the sources, knowing the credibility of a website, finding information from different parts, filtering relevant information from irrelevant, and finding up-to-date material. The findings have proved that they need to develop their research related information skills. Nevertheless, these findings are not uncommon. Head \& Eisenberg $(2009,2010)$ established that for $84 \%$ of their respondents, getting started was difficult. Cheunwattana et.al. (2012) also established that starting the research was difficult for $46 \%$.

\section{Conclusion and Recommendations}

The findings lead to the conclusion, that the agriculture undergraduates use search engines, Wikipedia and classmates often as information resources, use more self-taught methods to evaluate resources, consult classmates more often than any other group of people for help, and they have problems in research-related tasks. Under these circumstances, serious attention should be paid to the quality of the Information-seeking behavior of the agriculture students. These findings strongly establish that the agriculture students urgently need more support from the faculty and the librarians to improve their information-seeking behaviour if they are to exploit the rich library and internet-based information resources for their learning and research. Delving in to the training they receive in Information Literacy or library usage proved that $52 \%$ have not received any such training while $48 \%$ accepted they received such training. This training is limited to the 45-60 minute orientation programme provided once the new students enrolled in the faculty. Absence or lack of training in information skills can be identified as the main reason for the weaknesses in their information- seeking behaviour and the research practices.

Therefore, it is strongly recommended that the students be provided with adequate training in to use the information resources effectively and consult librarians for assistance when they need expertise to help them. They need to be trained in searching for information from 
reliable websites so that they can search beyond Wikipedia or Google. They also need to be trained to evaluate internet-based material as the most often used resource is search engines. Searching and evaluating skills will enable them to obtain more quality and relevant information from the internet. It is also recommended to provide training in the research process, so that the difficulties in research-related information tasks are minimized.

\section{References}

Adio, G. and Arinola, A.A. (2012). Information needs and information seeking behaviour of agricultural students at LAUTECH, Ogbomoso. Pacific Northwest Library Association Quarterly, 76. Retreived from WWW.pnla.org.

Burton, V.T. and Chadwick, S.A. (2000). Investigating the practices of stduent researchers: patterns of use and crietria for use on Internet and library sources. Computers and Composition, 17, 309-328 .

Cheunwattana, A. et.al. (2012).Survey of information literacy practices of college students in Thailand. Retrieved from http://www.albertkb.nl/mediapool/60/608240/data/IMILS_Final_Report_Rev.pdf.

Colon-Aguirre, M. and Fleming-May, R. A. (2012). You just type in what you are looking for: undergraduates' use of library resources vs. Wikipedia. Journal of Academic Librarianship, 38, 391-399.

Fidel, R. and Green, M.(2004). The many faces of accessibility: engineers' perfception of information sources. Information Processing and Management, 40, 563-581.

Hadimani, M.B. and Rajgoli, I.U. (2010). Assessing information literacy competency among undergraduate students of College of Agriculture, Raichur: a case study. DESIDOC Journal of Library and Information Technology, 30, 70-78.

Head, A. \& Eisenberg, M. (2009). Lessons learned: how college students seek information in the digital age. Retrieved from http://projectinfolit.org/pdfs/PIL_Fal12009_finalv_YR1_12_2009v2.pdf.

Head, A. \& Eisenberg, M. (2010). Truth be told: how college students evaluate and use information in the digital age. Retrieved from : http://projectinfolit.org/pdfs/PIL_Fall2010_Survey_FullReport1.pdf 
Ileperuma, S. and Mudannayake, I. (2008). Information gathering behaviour of undergraduate and postgraduate students in the Faculties of Agriculture and Science at University of Peradeniya. In Proceedings of the Peradeniya University Research Sessions, Sri Lanka. Vol. 10.

Kim, K. and Sin, S.J.(2007). Perceptions and selection of information sources by undergraduate students: effects of avoidant style, confidence and personal control in problem solving. The Journal of Academic Librarianship, 33, 655-665.

Kumar, S. (2009). Undergraduate perceptions of the usefulness of Web 2.0 in higher education: survey development. Retreived from :

plaza.ufl.edu/swapnak/ecel09kumar.pdf (accessed 29 May 2014).

Lee, J., Han, S. and Joo, S. (2008). The analysis of the information users' needs and information seeking behavior in the field of science and technology. Journal of the Korean Society for Information Management. 25, 127-141 .

Lee, J.Y., Paik, W. and Joo, S.(2012). Information resource selection of undergraduate students in academic search tasks. Information Research, 17.Retreived from : http://informationr.net/ir/17-1/paper511.html (accessed on 06 May 2013).

Lim, S. (2009). How and Why Do College Students Use Wikipedia? .Journal of the American Society for Information Science and Technology, 60, 2189-2202 .

Liu, Z., and Yang, Z.Y.(2004). Factors influencing distance-education graduate students' use of information sources. The Journal of Academic Librarianship, 30, 24-35.

Rhoades, E.B., Irani, T. T. R. and Myers, B.E. (2008). Internet as an information source: attitudes and usage of students enrolled in a College of Agriculture course. Journal of Agricultural Education, 49, 108-117.

Xie, I and Joo, S. (2009). Selection of information sources: types of tasks, accessibility, and familiarity of sources. In Proceedings of the American Society for Information Science and Technology,46, (pp.1-18).

Zakaria, M.H.,Watson, J. and Edwards, S.L. (2010). Investigating the use of Web 2.0 technology by Malaysian students. Multicultural Education and Technology Journal, 4(1), 17-29.

Financial assistance given by University of Peradeniya (Grant No. RG/2012/58/L) is acknowledged. 